\title{
Ruth Sandwell and Amy von Heyking, eds. Becoming a History Teacher: Sustaining Practices in Historical Thinking and Knowing
}

Toronto: University of Toronto Press, 2014. xii, 345 pp.

\section{Paul Zanazanian}

McGill University

Over the last decade, many Canadian history educators have embraced disciplinebased approaches in their teaching. The development of an extremely useful teaching methodology, such as the one introduced in The Big Six Historical Thinking Concepts by Seixas and Morton (2013), has further facilitated this interest by providing key user-friendly historical thinking concepts designed to engage teachers and students in doing history through an inquiry-based approach. Despite these advances, the teaching of history in many Canadian provinces remains rather conventional, with teachers passively transferring dates, names, and events, or, at times, simply "teaching to the test." Becoming a History Teacher: Sustaining Practices in Historical Thinking and Knowing addresses challenges and looks into the different ways that historians and teacher educators can assist pre-service and regular history teachers support best practices in the long run.

With pieces from Canada's top thinkers in this area, the book will have great implications for key actors, from academics and teachers to policy-makers and stakeholders. It will definitely influence how such individuals think about history education, as it has informed how I engage in my own practice. While the book's claims are strong and clearly laid out with insightful solutions, its recommendations constitute a tall order. In terms of feasibility, the required tasks could seem rather daunting and may leave readers feeling overwhelmed.

The book offers research-based reflections and practical illustrations on how to best learn and cultivate historical thinking in schools. It is divided into three main sections according to the "before," "during," and "after" stages of history teachers" path towards becoming professionals. All the contributors address an overarching question: why history teachers seem to be on the periphery of their community of 
practice, rather than on an in-bound trajectory to the core of the profession - a core that ideally incorporates historical thinking and adequate pedagogical content knowledge for teaching it. Alan Sears's piece frames this conversation, giving the book its original flavour. He presents three main obstacles that impede teachers from properly grasping and teaching historical thinking: little-to-no familiarity with the workings of history as a discipline, powerful cognitive frames or mental representations of what history is and how it should be taught, and strongly ingrained teacher identities as passive transferers of content knowledge. As a solution, Sears calls for cross-boundary exchanges among three core professional communities. Historians, history teachers, and history teacher educators are to work together, with the latter functioning as brokers to help the other two groups adopt mutually beneficial mindsets and practices. The desired outcome is the dismantling of strongly ingrained cognitive frames that hinder the teaching of historical thinking. The road to getting there, though, is complex and requires sustained interest and motivation across all three communities.

To positively foster this exchange, the book's contributors support the long view of teacher education for understanding and teaching historical thinking. Attaining this objective, however, requires major reforms, a radical shift in how the three communities interact. Innovative pedagogical practices that cut across professional boundaries are needed. Some authors believe historians are best placed for initiating such activities. As Ruth Sandwell argues, historians hold great potential in influencing how student teachers understand and even teach historical thinking through their undergraduate courses and should thus embrace this responsibility as a means of boosting Canada's health as a pluralistic democracy. Although it is not clear whether historians would identify with such a call, let alone whether they meticulously follow historical thinking guidelines in their work and would be open to teaching it, the point is certainly valid.

In their turn, teacher educators are asked to improve their modeling practices, to offer finer pedagogical information to novices, and to engage in long-term professional development programs to help the latter better understand and teach history as a discipline. This also will not be easy. Peers or institutional teaching cultures represent forms of resistance teachers often encounter, making it harder to fully adopt desired changes, despite positive evidence that pre-service teachers can grasp historical thinking and its pedagogical implications. Student teachers require help in creating relevant learning activities or confronting uncertainties in their ability to challenge their own students' cognitive frames. Acknowledging the need to transform their teacher identities and practice is not always straightforward, nor is appreciating the intellectual demands of history teaching. Their differing rationales may also divert from embracing the idea of in-bound trajectories, and their own eventual teaching cultures in schools may also constitute unanticipated obstacles.

Rich in information, I know how I would incorporate some of the book's ideas into my own work. As one of Quebec's few English-language social studies teacher educators, I am developing narrative tools to help make room for the province's English-speaking minority in history classrooms. Similar to what Stéphane Lévesque and Kent den Heyer suggest, my students question and historicize their cognitive 
frames regarding their personal and professional identities. They learn about the underlying politics of narrative control and resistance. And they account for their knowledge claims when articulating their sense of purpose. Rose Fine-Meyer's take on place-based learning is also beneficial. Her approach would develop concrete strategies to promote historical understanding and cross-boundary projects for prompting better connectivity among students to their local and larger communities. Finally, Sears's conceptualization of professional learning communities has made me visualize English-speaking Quebec as a community of practice, with potential overlaps with historians' and history teachers' own communities for performing cross-boundary work needed for making room and vitalizing this historic minority.

I started reading this book with skepticism. Although I am still hesitant regarding the feasibility of what needs to be done, I am not disillusioned. Many cognitive, practical, and structural obstacles exist that make thinking and being able, motivated, and committed to teaching historical thinking a difficult and highly complex task. Bringing change demands effort, motivation, and concerted action by committed historians and history educators. The key would be to remain true to the core principles linking historical thinking to democratic citizenship, to maintain dialogue across different professional boundaries, and to have individuals like myself engage in concrete cross-boundary activities, instead of merely talking about their importance. All will be done one step at a time. The book will have an impact. The conversation has started. 